\title{
Clinical and pharmacological properties of new oral anticoagulants for the prevention of cerebral thromboembolism: Factor Xa and thrombin inhibitors ${ }^{*}$
} \author{
Tobias Back ${ }^{4}$ \\ ${ }^{1}$ Department of Neurology, Philipps-University Marburg, Marburg, Germany \\ ${ }^{2}$ Clinic of Neurology, Marienhospital Kevelaer, Kevelaer, Germany \\ ${ }^{3}$ Department of Neurology, Kreisklinikum Siegen, Siegen, Germany \\ ${ }^{4}$ Department of Neurology, Saxon Hospital Arnsdorf, Arnsdorf/Dresden, Germany \\ Email: yaroslav.winter@med.uni-marburg.de
}

Yaroslav Winter $^{1}$, Richard Dodel ${ }^{1}$, Alexei Korchounov ${ }^{2}$, Martin Grond ${ }^{3}$, Wolfgang H. Oertel ${ }^{1}$,

Received 26 September 2011; revised 4 November 2011; accepted 28 November 2011

\begin{abstract}
Vitamin $\mathrm{K}$ antagonists, such as warfarin and phenprocoumon, are the first-line oral anticoagulants for primary and secondary prevention of cerebral embolism in patients with atrial fibrillation. Although vitamin $\mathrm{K}$ antagonists can significantly decrease the risk of stroke, their use is limited by several important drawbacks, such as a narrow therapeutic window, the risk of intracranial and gastrointestinal bleeding, interactions with a number of drugs and nutrients, and the need for regular laboratory tests for therapy adjustment. Currently, new oral anticoagulants, such as direct thrombin inhibitors (e.g., dabigatran) and direct factor $\mathrm{Xa}$ inhibitors (e.g., apixaban, rivaroxaban), are being developed and tested in clinical trials. Dabigatran and rivaroxaban were recently approved for prevention of cerebral embolism in patients with atrial fibrillation. The advantages of dabigatran in comparison to warfarin are a lower rate of major bleedings with dabigatran 110 mg bid, a better efficacy with dabigatran $150 \mathrm{mg}$ bid, no clinically relevant interactions with other drugs and no need for routine coagulation monitoring. The disadvantages are the absence of antidote and the absence of routine laboratory tests for precise measurements of anticoagulant effect of direct thrombin/ factor Xa inhibitors. This review will focus on thrombin and factor $X a$ inhibitors, which are new and promising oral anticoagulants for the prevention of cerebral embolism. We will discuss their pharmacological and clinical properties and provide the most recent updates on their clinical trials.
\end{abstract}

${ }^{*}$ Conflict of interest: Nothing to declare regarding the content of this article.
Keywords: Thrombin Inhibitor; Factor Xa Inhibitor; Dabigatran; Rivaroxaban; Cerebral Embolism; Atrial Fibrillation

\section{INTRODUCTION}

Stroke is a major source of mortality and long-term disability worldwide [1]. Stroke of thromboembolic origin is associated with prolonged hospitalization and a worse functional outcome [2]. Non-valvular atrial fibrillation is a major risk factor for cerebral embolism (odds ratio of 1.9 - 18.2 depending on the presence of other vascular risk factors) [3]. Patients with non-valvular atrial fibrillation have a fivefold increased risk of developing ischemic stroke [4]. Non-valvular atrial fibrillation is the most common cardiac arrhythmia, affecting $1 \%$ of the general population, and its prevalence increases with age. Atrial fibrillation can be found in approximately $10 \%$ of individuals aged 80 years and older [5]. Anticoagulant therapy is indicated in patients with atrial fibrillation and at least one moderate risk factor (e.g., hypertension, diabetes mellitus, heart failure) [6,7]. For decades, vitamin $\mathrm{K}$ antagonists, such as warfarin and phenprocoumon, have been the only oral anticoagulants for stroke prevention in patients at risk of cerebral embolism. Although they can decrease the risk of stroke by up to $70 \%$, they have several important limitations. Vitamin $\mathrm{K}$ antagonists have a narrow therapeutic window and require regular dose adjustments by monitoring the anticoagulant effect. Other disadvantages are the risk of major intracranial and gastrointestinal bleeding complications, interactions with a number of drugs and nutrients, slow onset and offset of action and some other side effects such as coumarininduced hepatitis [8,9]. Antiplatelet drugs, such as acetylsalicylic acid and clopidogrel, were recommended for 
patients with atrial fibrillation who had contraindications for vitamin-K antagonists [8]. However, antiplatelet agents only provide very modest protection against cerebral embolism.

New drugs such as direct thrombin inhibitors (e.g., dabigatran), direct factor Xa inhibitors (e.g., apixaban, rivaroxaban) or indirect factor Xa inhibitors (e.g., fondaparinux, idraparinux, indrabiotaparinux) were recently developed and are currently being tested in clinical trials. Dabigatran and rivaroxaban were recently approved for the prevention of thromboembolism in patients with atrial fibrillation.

This review will focus on thrombin inhibitors and factor Xa inhibitors, which are new and promising oral anticoagulants in the most advantages stages of clinical development. We will discuss the pharmacological and clinical properties of these substances and provide the most recent updates on their clinical trials.

\section{CONVENTIONAL DIRECT UND INDIRECT ANTICOAGULANTS}

Coumarins, or 4-hydroxycoumarins, are the most commonly used vitamin $\mathrm{K}$ antagonists and, until recently, were the only oral anticoagulants available for clinical use. First introduced more than half a century ago, they are currently represented by warfarin, phenprocoumon, acenocoumarol and dicoumarol (Figure 1). In the USA, warfarin is a common oral anticoagulant, whereas in most European countries phenprocoumon is more frequently used. The precursor of these anticoagulants, coumarin, is a chemical compound found in many plants. The name coumarin is derived from a French word "coumarou" for the tonika bean (Dipteryx odorata), which has a high concentration of this compound. It has a sweet odour and has been used in perfumes and in food flavouring additives since 1882, until it was banned due to concerns about hepatotoxicity. Although coumarin itself does not show anticoagulant activity, it is trans- formed into the anticoagulant dicoumarol by a number of fungi. This natural anticoagulant was responsible for the cases of bleeding in cattle that ate sweet clover silage [10].

Warfarin is a synthetic derivative of coumarin and was initially used as a rodenticide before its therapeutic value was recognized. Warfarin and other pharmaceuticals derived from coumarin inhibit the enzyme vitamin $\mathrm{K}$ epoxide reductase, which converts vitamin $\mathrm{K}$ to its active form. The amount of available vitamin $\mathrm{K}$ in the body decreases, resulting in reduction of the activity of vitamin K-dependent enzymes involved in the transformation of certain clotting factors into their active forms [8]. Warfarin and other vitamin $\mathrm{K}$ antagonists have a number of disadvantages, such as diverse interactions with other drugs (e.g., antiepileptics) and nutrients, complex pharmacokinetics and pharmacodynamics, and a narrow therapeutic window. They also have potential teratogenicity and can show hepatotoxicity in up to $2 \%$ of patients [11]. However, oral anticoagulants are not usable in pregnancy.

In contrast to coumarins, heparins are indirect anticoagulants that potentiate the action of antithrombin. Unfractionated heparin (UH) is administered intravenously. It binds to plasma proteins, which can result in variable anticoagulant actions. Patients on heparin are at risk of osteoporosis and heparin-induced thrombocytopenia [12]. Low-molecular-weight heparins (LMWH) are obtained from UH by various methods of fractionation and have an average molecular weight of less than 8000 Da [12]. They are administered by once or twice daily dosing by subcutaneous injection. In comparison to UH, their coagulation parameters do not require monitoring, and they have a smaller risk of osteoporosis and a smaller risk of heparin-induced thrombocytopenia.

\section{NEW ANTICOAGULANTS}

The new anticoagulants are synthetic drugs that were
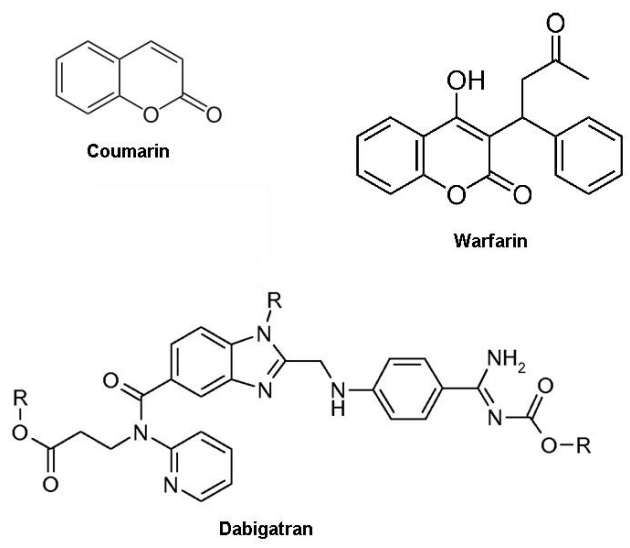
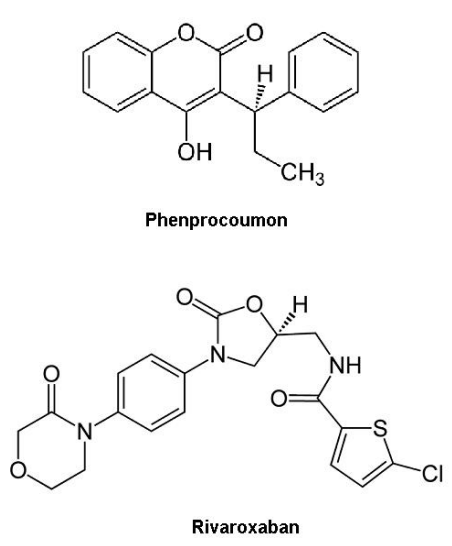

Figure 1. Chemical structure of coumarin, vitamin K antagonists and new anticoagulants. 
recently introduced in an attempt to overcome the limitations of vitamin $\mathrm{K}$ antagonists and heparin. They were developed to act against one clotting factor by selective and reversible binding to the active site of enzymes participating in the coagulation cascade. Reversible inhibition of clotting factors is an important feature for lowering the risk of bleeding complications. The following classes of anticoagulants are currently the main focus of pharmacological research: direct thrombin inhibitors (e.g., dabigatran) [13], direct factor Xa inhibitors (e.g., rivaroxaban, apixaban, edoxanab) [14-16] and indirect factor Xa inhibitors (e.g., fondaparinux, idraparinux, indrabiotaparinux) [17].

Thrombin is the key enzyme at the end of the coagulation pathway. In addition, it participates in platelet activation and interacts with fibrinolysis and inflammatory processes. The direct inhibition of thrombin can affect all of its properties and, therefore, it is less predictable than the inhibition of factor Xa. However, the pleiotropic effect of thrombin inhibition may also confer advantages [18].

Factor $\mathrm{Xa}$ is a coagulation factor that acts at the convergence point of the intrinsic and extrinsic coagulation pathways (Figure 2). Due to its strategic location, factor $\mathrm{Xa}$ is an attractive target for anticoagulant agents. One molecule of factor Xa catalyses is the generation of more than 1000 thrombin molecules [19]. Factor Xa inhibitors reduce the thrombin burst in the propagation phase of the coagulation cascade. The direct inhibition of factor $\mathrm{Xa}$ does not reduce the activity of the existing thrombin. This action might be able to decrease the risk of bleeding, although this issue is still controversial [20].

\section{DIRECT THROMBIN INHIBITORS}

\section{Dabigatran}

Dabigatran is an oral, specific, reversible thrombin inhibitor (Figure 2). It is a very polar hydrophilic molecule that is not bioavailable after oral administration (Figure 1). Dabigatran is available as a prodrug, dabigatran etexilate, which increases the bioavailability to 6.5\%. Dabi- gatran etexilate is converted by plasma esterases to its active metabolite dabigatran. The peak plasma level of dabigatran is achieved within 1 - 2 hours after oral administration and the half-life of dabigatran is about 14 17 hours [21]. The plasma protein binding is 35\%. The predominant route of drug elimination is renal (80\%). About $20 \%$ of dabigatran is metabolized in the liver with no involvement of cytochrome P450 enzymes [13]. The pharmacological profile of dabigatran in comparison to other new oral anticoagulants is shown in Table 1. There are no reported clinically relevant interactions of dabigatran with other drugs, except for amiodarone, verapamil and quinidine. In comparison to vitamin $\mathrm{K}$ antagonists, dabigatran does not require routine coagulation monitoring $[13,22]$. In comparison to ximelagatran, dabigatran does not induce heptatotoxicity, as far as is currently known.

The efficacy and safety of dabigatran for the prevention of cerebral and systemic embolism was investigated in patients with atrial fibrillation in a randomized evaluation of long-term anticoagulant therapy (RE-LY) [23]. This phase III study ( $\mathrm{n}=18,113$ ) was designed as a prospective, randomized, controlled parallel group, noninferiority trial. The patients with non-valvular atrial fibrillation were randomized to receive $110 \mathrm{mg}$ dabigatran twice daily (bid), 150 mg dabigatran bid or warfarin

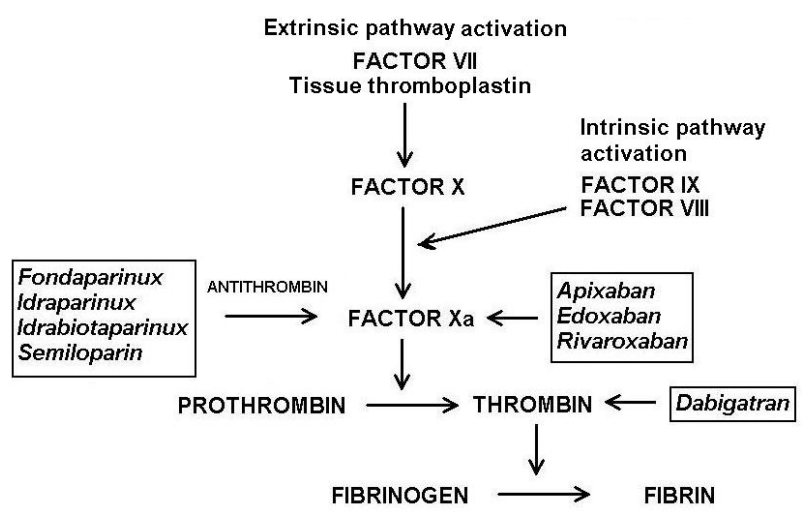

Figure 2. Targets of inhibition of different anticoagulants.

Table 1. Pharmacological profile of new oral anticoagulants compared to warfarin [13-16,20,32,33].

\begin{tabular}{|c|c|c|c|c|c|}
\hline & Apixaban & Dabigatran & Endoxaban & Rivaroxaban & Warfarin \\
\hline Thrombin/factor Xa inhibitor & factor $\mathrm{Xa}$ & thrombin & factor $\mathrm{Xa}$ & factor $\mathrm{Xa}$ & VKA \\
\hline Bioavailability (\%) & 50 & 6.5 & 50 & $90-100$ & 100 \\
\hline Plasma protein binding (\%) & 87 & 35 & $40-59$ & 95 & 99.5 \\
\hline Half-life (hours) & $10-14$ & $14-17$ & $9-11$ & $7-11$ & 40 \\
\hline Dosage & bid & bid & od & od & od \\
\hline Liver metabolism (\%) & N.A. & 20 & N.A. & 66 & $99 \%$ \\
\hline Renal elimination (\%) & 25 & 80 & 35 & 33 & $1 \%$ \\
\hline
\end{tabular}

Abbreviations: VKA: vitamin K antagonist; N.A.: data not available in the literature; od: once daily; bd: twice daily; $\mathrm{T}_{\text {max }}$ : time to peak plasma concentration. 
(INR: 2.0 - 3.0). Both doses of dabigatran were blinded, whereas warfarin was administered in an open-label manner. The annual occurrence of cerebral and systemic embolism was $1.53 \%$ in patients on $110 \mathrm{mg}$ dabigatran bid, $1.11 \%$ in patients on $150 \mathrm{mg}$ dabigatran bid and $1.69 \%$ in patients on warfarin. The relative risk (RR) was 0.91 (95\% CI: 0.74 - 1.11) for the comparison of $110 \mathrm{mg}$ dabigatran bid versus warfarin $(\mathrm{p}<0.001$ for non-inferiority and $\mathrm{p}=0.34$ for superiority) and $0.66(95 \% \mathrm{CI}$ : 0.53 - 0.82) for the comparison of $150 \mathrm{mg}$ dabigatran bid versus warfarin ( $\mathrm{p}<0.001$ for superiority). The annual rate of major bleeding complications was $3.36 \%$ in patients randomized to receive warfarin, $2.71 \%$ in patients on $110 \mathrm{mg}$ dabigatran bid $(\mathrm{p}=0.003)$ and $3.11 \%$ in patients on $150 \mathrm{mg}$ dabigatran bid ( $\mathrm{p}=0.31$ ). In summary, $110 \mathrm{mg}$ dabigatran bid showed similar efficacy and better safety outcomes compared to warfarin (20\% less major bleedings). Dabigatran at $150 \mathrm{mg}$ bid was superior to warfarin in terms of efficacy outcomes (34\% less embolic events) and it had a similar rate of major bleeding events as warfarin. Compared to warfarin, the relative risk of brain haemorrhage on $110 \mathrm{mg}$ dabigatran bid was $69 \%$ lower and on $150 \mathrm{mg}$ dabigatran bid it was 60\% lower.

Table 2 shows a comparison of the number needed to treat (NNT) and the number needed to protect (NNP) for dabigatran versus warfarin and acetylsalicylate acid. The NNT of 173 for the comparison of dabigatran versus warfarin means that one cerebral or systemic embolic event could be prevented, if 173 patients changed from warfarin to dabigatran.

Based on results of the RE-LY study, dabigatran was approved for the prevention of cerebral and systemic embolism in patients with atrial fibrillation in the USA, Canada, Japan and Europe. It was also included in the last guidelines updates of the American College of Cardiology, the American Heart Association and the Heart Rhythm Society as an alternative to warfarin in the treatment of patients with atrial fibrillation [24]. A summary of the phase III clinical trials with direct thrombin inhibitors and direct factor Xa inhibitors is shown in Table 3.

Dabigatran has also been shown to be effective in the treatment of acute deep vein thrombosis and pulmonary embolism. The most frequent minor side effect of dabigatran is dyspepsia. Among disadvantages of dabigatran are the absence of antidote and the absence of routine laboratory tests for the measurement of anticoagulant effect in case of overdose. As the protein binding of dabigatran is low, it can be dialysed with the removal of approximately $60 \%$ of substance over 3 hours. In addition no data on compliance are available for dabigatran.

\section{DIRECT FACTOR XA INHIBITORS}

\subsection{Rivaroxaban}

Rivaroxaban is an oral direct factor Xa inhibitor, which has a 10,000-fold higher selectivity for factor Xa than for

Table 2. Number needed to treat (NNT) and number needed to protect (NNP)*.

\begin{tabular}{ccccc}
\hline & \multicolumn{2}{c}{ NNT } & NNP \\
\hline & Warfarin (INR 2.0 - 3.0) & Acetylsalicylate acid (81 - 325 mg) & Warfarin (INR 2.0 - 3.0) & Acetylsalicylate acid (81 - 325 mg) \\
Dabigatran & 173 & 46 & 154 & 397 \\
Apixaban & 303 & 52 & 104 & $-1692^{* * *}$ \\
Rivaroxaban & 333 & 53 & $-500^{* *}$ & 90 \\
Warfarin & & 63 & & 111 \\
\hline
\end{tabular}

"NNT and NNP were calculated based on published data of the following studies: RE-LY[23], ROCKET AF[25], ARISTOTLE[27]; ${ }^{* *}$ negative figure shows that more major bleeding complications occur under rivaroxabin than under warfarin; ${ }^{* * *}$ negative figure shows that more major bleeding complications occur under acetylsalicylate acid than under apixaban.

Table 3. Clinical trials (phase III) of oral thrombin and factor Xa inhibitors in stroke prevention.

\begin{tabular}{|c|c|c|c|c|c|c|}
\hline Substance & Study acronym & Design & $\begin{array}{l}\text { Number of } \\
\text { participants }\end{array}$ & Comparator & $\begin{array}{c}\text { Duration of } \\
\text { study }\end{array}$ & Current status \\
\hline \multirow{2}{*}{ Apixaban } & ARISTOTLE [27] & $\begin{array}{l}\text { Randomized, double-blind, } \\
\text { non-inferiority }\end{array}$ & 18,201 & Warfarin (INR 2.0 - 3.0) & 1.8 years & completed \\
\hline & AVERROES [28] & $\begin{array}{l}\text { Randomized, double-blind, } \\
\text { superiority }\end{array}$ & 5600 & Acetylsalicylic acid & 3 years & $\begin{array}{l}\text { early termi- } \\
\text { nation }\end{array}$ \\
\hline Endoxaban & ENGAGE AF-TIMI 48 [34] & $\begin{array}{l}\text { Randomized, double-blind, } \\
\text { non-inferiority }\end{array}$ & 20,500 & Warfarin (INR 2.0 - 3.0) & 2 years & ongoing \\
\hline Rivaroxaban & ROCKET AF [25] & $\begin{array}{l}\text { Randomized, double-blind, } \\
\text { non-inferiority }\end{array}$ & 14,264 & Warfarin (INR 2.0 - 3.0) & 4 years & completed \\
\hline
\end{tabular}


other serine proteases (Figures $\mathbf{1}$ and 2). The pharmacological properties of rivaroxaban are shown in Table 1. The oral bioavailability of rivaroxaban is $90 \%-100 \%$. The peak plasma level is reached in about 3 hours after digestion and the terminal half-life is $7-11$ hours. The half-life is prolonged in the elderly and in cases of renal insufficiency [20]. About 95\% binds to plasma proteins, with serum albumin representing the main binding component. Its pharmacokinetic and pharmacodynamics profiles have been proven to be predictable for daily doses of 5 to $80 \mathrm{mg}$. Rivaroxaban is metabolized in the liver (66\%), with the involvement of cytochrome P450.

The efficacy of rivaroxaban has been proven for the treatment of acute and recurrent deep vein thrombosis over a period of 24 months. The safety outcomes of rivaroxaban were found to be comparable with warfarin.

In a recent randomized double-blind study of patients with atrial fibrillation, rivaroxaban (20 mg daily or 15 $\mathrm{mg}$ daily in creatinine clearance $30-49 \mathrm{~mL} / \mathrm{min}$ ) was compared with warfarin (INR 2-3) [25]. The mean follow-up of this study, with approximately 7130 patients per treatment group, was 12 months and the mean CHAD2 score was 3.5 in each group. In patients on rivaroxaban, the rate of cerebral and systemic embolic events was $1.7 \%$ per year versus $2.2 \%$ per year in the patients on warfarin (hazard ratio (HR) 0.79, 95\% CI: $0.66-0.96$, non-inferiority $\mathrm{p}<0.001)$. In the intentionto-treat analysis the annual rate of stroke or systemic embolism was $2.1 \%$ under rivaroxaban and $2.4 \%$ under warfarin (OR: 0.88, 95\% CI: $0.74-1.03$, p $<0.001$ for non-inferiority and $\mathrm{p}=0.12$ for superiority). The rate of major bleeding complications did not differ between warfarin and rivaroxaban $(p=0.44)$. Intracerebral haemorrhages occurred less frequently in patients with rivaroxaban than in patients with warfarin $(0.5 \%$ versus $0.7 \%$ per year, HR 0.59, 95\% CI: $0.37-0.93, \mathrm{p}=0.024$ ).

Currently, rivaroxaban is also being investigated in the treatment of acute pulmonary embolism and in the prevention of ischaemic events in unstable angina pectoris (phase III trial) [26].

\subsection{Apixaban}

Apixaban is a selective and reversible inhibitor of factor Xa and pro-thrombinase activity [14-16]. It has an oral bioavailability of $50 \%$ and is rapidly absorbed with a peak plasma level being achieved 3 - 4 hours after intake. The mean half-life was found to range between 10 and 14 hours [14]. Apixaban has various pathways of elimination, such via the kidneys, the intestinal route and oxidative metabolism. Cytochrome P450 inhibitors can increase the plasma level of apixaban. Other pharmacological characteristics of apixaban are shown in Table 1.

Apixaban for the prevention of cerebral and systemic embolism was investigated in two ongoing, randomized double-blind studies. The Stroke and Other Thromboembolic Events in Atrial Fibrillation (ARISTOTLE) study randomized over 18,000 patients with atrial fibrillation to receive apixaban (5 $\mathrm{mg}$ bid) or warfarin (INR 2.0 - 3.0) [27]. The primary objective is the non-inferiority of apixaban regarding the risk reduction of stroke and systemic embolism. The annual rate of stroke and systemic embolism was $1.27 \%$ in patients on apixaban and $1.60 \%$ in patients on warfarin (OR 0.79, 95\% CI: $0.66-0.95, \mathrm{p}<0.001$ for non-inferiority and $\mathrm{p}=0.01$ for superiority). Apixaban caused fewer major bleeding complications than warfarin (OR 0.69, 95\% CI: 0.60 $0.80, \mathrm{p}<0.001)$. The annual rate of haemorrhagic stroke was $0.24 \%$ in the apixaban arm and $0.47 \%$ in the warfarin arm (OR 0.51, 95\% CI: 0.35 - 0.75, p < 0.001, p < $0.001)$. The disadvantage of the ARISTOTLE study was that warfarin arm was not blinded.

The AVERROES study evaluated apixaban (5 mg bid) versus acetylsalicylic acid (81 - 324 mg once daily (od)) for the prevention of stroke in patients with atrial fibrillation $(\mathrm{n}=5600)$ who failed on, or were unsuitable for, vitamin $\mathrm{K}$ antagonist treatment [28]. The annual rates of cerebral and systemic embolism were $1.6 \%$ and $3.7 \%$ in patients on apixaban and acetylsalicylic acid, respectively (HR 0.45, 95\% CI: $0.32-0.64, \mathrm{p}<0.001$ ). The rate of major bleeding complications, haemorrhagic stroke, myocardial infarction and death was similar in both treatment arms [29].

Three studies (Apixaban Dosed Orally versus Anticoagulation with Enoxoparin [ADVANCE-1, -2 and -3]) evaluated apixaban for the prevention of venous thromboembolism in patients with major orthopaedic interventions. In the ADVANCE-1 study, $2.5 \mathrm{mg}$ apixaban bid failed to show non-inferiority compared to $30 \mathrm{mg}$ enoxaparin (LMWH) bid regarding the primary endpoint (occurrence of deep vein thrombosis, pulmonary embolism and all-cause mortality) in patients after total knee replacement surgery [30]. The ADVANCE-2 and -3 studies showed superiority of $2.5 \mathrm{mg}$ abixaban od compared to $40 \mathrm{mg}$ enoxaparin od for the prevention of deep vein thrombosis, pulmonary embolism and thromboembolism-related mortality in patients who underwent total knee and total hip replacement surgery [31].

\subsection{Endoxaban}

Endoxaban (DU-176b) is an oral, direct, specific inhibitor of factor Xa (Figure 2). It has a bioavailability of approximately $50 \%$ and the peak plasma concentration of $60 \mathrm{mg}$ orally administered endoxaban is achieved after 1.5 hours [32]. The pharmacological profile of endoxaban is shown in Table 1. Endoxaban has no clinically relevant interactions with food [33]. Data on interactions 
with other drugs are not currently available.

In a phase II study for the prevention of cerebral embolism in patients with atrial fibrillation, $30 \mathrm{mg}$ and 60 mg endoxaban bid both showed a higher rate of major bleeding complications compared to warfarin (INR 2.0 3.0). Endoxaban administered once daily at a lower dose (30 mg od and $60 \mathrm{mg}$ od) was associated with a similar rate of major bleeding complications and cerebral embolic events compared to warfarin. The phase III study is currently comparing $30 \mathrm{mg}$ and $50 \mathrm{mg}$ endoxaban od with warfarin for the prevention of cerebral and systemic embolism in nearly 20,500 patients with atrial fibrillation [34]. In fact, a number of other direct factor Xa inhibitors, such as eribaxan, betrixaban (PRT054021), LY517717, TAK-422 and YM150, are currently being investigated in phase II studies [35-40].

\section{INDIRECT FACTOR XA INHIBITORS}

Fondaparinux was the first synthetically generated factor Xa inhibitor (Figure 2). Similar to other heparins, fondaparinux is dependent on the presence of antithrombin. It mediates the conformational change of antithrombin, which results in a 700 times greater affinity compared to heparin [41]. Fondaparinux is approved for treatment and the prevention of venous thrombosis, pulmonary embolism and unstable angina pectoris [42]. A number of derivatives of fondaparinux, such as idraparinux, idrabiotaparinux and semiloparin, are currently under development [17].

\section{CONCLUSION}

Direct thrombin inhibitors and direct factor Xa inhibitors have shown promising results in clinical trials of stroke prevention to become valuable alternatives to vitamin $\mathrm{K}$ antagonists in the near future. The introduction of these innovative substances to the market is an important milestone in the development of safe and patient-oriented strategies for oral anticoagulation. For decades, vitamin $\mathrm{K}$ antagonists were the only therapeutic option for oral anticoagulation in patients with atrial fibrillation and an increased risk of cerebral embolism. Due to a number of disadvantages of vitamin $\mathrm{K}$ antagonists, such as routine coagulation monitoring, interactions with food and a number of drugs and bleeding complications, there is a need for new substances with a more favourable pharmacological profile. At present, the best evidence is available for dabigatran and rivaroxaban. Only a few months after approval of dabigatran by the FDA, it has entered the US guidelines of cardiology as an alternative to warfarin for preventing cerebral and systemic thromboembolism in patients with atrial fibrillation. Recently, rivaroxaban was also approved for the prevention of embolism in atrial fibrillation. In the near future, the ap- proval of apixaban and endoxaban for oral anticoagulation in atrial fibrillation is expected. The development of new therapeutics is extremely important in the treatment of thromboembolic strokes, which often result in severe functional disability and neurological sequelae, such as post-stroke epilepsy [43] or post-stroke dementia [44].

Although many thousands of patients have already been treated with new thrombin inhibitors and factor Xa inhibitors, these new oral anticoagulants need to be further investigated in post-approval studies in order to evaluate treatment adherence in "real-life" settings and the safety aspects in different subgroups of patients. In addition, limitations of studies with new oral anticoagulants include the fact that warfarin arm was not blinded and a substantial proportion of patients did not achieve therapeutical range of INR $2-3$. Also, the question of antagonistic treatment options in the case of bleeding complications has to be addressed.

\section{REFERENCES}

[1] Wolf, P., Kannel, W. and D’Agostino, R. (1998) Epidemiology of stroke. In: Ginsberg, M. and Bogousslavsky, J., Eds., Cerebrovascular Disease: Pathophysiology, Diagnosis and Management, Blackwell Science, Malden, 834-850.

[2] Winter, Y., Wolfram, C., Schaeg, M., et al. (2009) Evaluation of costs and outcome in cardioembolic stroke or TIA. Journal of Neurology, 256, 954-963. doi:10.1007/s00415-009-5053-2

[3] Gage, B.F., Waterman, A.D., Shannon, W., et al. (2001) Validation of clinical classification schemes for predicting stroke: Results from the national registry of atrial fibrillation. Journal of the American Medical Association, 285, 2864-2870. doi:10.1001/jama.285.22.2864

[4] Wolf, P.A., Mitchell, J.B., Baker, C.S., Kannel, W.B., and D'Agostino, R.B. (1998) Impact of atrial fibrillation on mortality, stroke, and medical costs. Archives of Internal Medicine, 158, 229-234. doi:10.1001/archinte.158.3.229

[5] Lloyd-Jones, D.M., Wang, T.J., Leip, E.P., et al. (2004) Lifetime risk for development of atrial fibrillation: The Framingham heart study. Circulation, 110, 1042-1046. doi:10.1161/01.CIR.0000140263.20897.42

[6] Fuster, V., Ryden, L.E., Cannom, D.S., et al. (2006) ACC/AHA/ESC 2006 guidelines for the management of patients with atrial fibrillation: A report of the American college of cardiology/American heart association task force on practice guidelines and the European society of cardiology committee for practice guidelines (writing committee to revise the 2001 guidelines for the management of patients with atrial fibrillation): Developed in collaboration with the European heart rhythm association and the heart rhythm society. Circulation, 114, 257-354.

[7] DGN, DSG (Germany Neurological Society and German Stroke Society). (2008) Primary and secondary pervention of cerebral ischemic events. In: Diener, H.C. and 
Putzki, N., Eds., Guidelines for Diagnostics and Therapy in Neurology, 4th Edition, Georg Thieme Stuttgart, New York, 261-287.

[8] Ansell, J., Hirsh, J., Hylek, E., et al. (2008) Pharmacology and management of the vitamin $\mathrm{K}$ antagonists: American college of chest physicians evidence-based clinical practice guidelines (8th Edition). Chest, 133, 160S-198S. doi:10.1378/chest.08-0670

[9] Singer, D.E., Albers, G.W., Dalen, J.E., et al. (2004) Antithrombotic therapy in atrial fibrillation: The seventh American college of clinical pharmacy conference on antithrombotic and thrombolytic therapy. Chest, 126, 429S-456S. doi:10.1378/chest.126.3 suppl.429S

[10] Bye, A. and King, H.K. (1970) The biosynthesis of 4-hydroxycoumarin and dicoumarol by aspergillus fumigatus fresenius. Biochemical Journal, 117, 237-245.

[11] Schimanski, C.C., Burg, J., Mohler, M., et al. (2004) Phenprocoumon-induced liver disease ranges from mild acute hepatitis to (sub-) acute liver failure. Journal of Hepatology, 41, 67-74. doi:10.1016/j.jhep.2004.03.010

[12] Hirsh, J., Bauer, K.A., Donati, M.B., et al. (2008) Parenteral anticoagulants: American college of chest physicians evidence-based clinical practice guidelines (8th Edition). Chest, 133, 141S-159S.

[13] Stangier, J. (2008) Clinical pharmacokinetics and pharmacodynamics of the oral direct thrombin inhibitor dabigatran etexilate. Clinical Pharmacokinetics, 47, 285-295.

[14] Raghavan, N., Frost, C.E., Yu, Z., et al. (2009) Apixaban metabolism and pharmacokinetics after oral administration to humans. Drug Metabolism and Disposition, 37, 74-81.

[15] Shantsila, E. and Lip, G.Y. (2008) Apixaban, an oral, direct inhibitor of activated factor Xa. Current Opinion in Investigational Drugs, 9, 1020-1033.

[16] Wong, P.C., Crain, E.J., Xin, B., et al. (2008) Apixaban, an oral, direct and highly selective factor Xa inhibitor: In vitro, antithrombotic and antihemostatic studies. Journal of Thrombosis and Haemostasis, 6, 820-829.

[17] Harenberg, J. (2009) Development of idraparinux and idrabiotaparinux for anticoagulant therapy. Thrombosis and haemostasis, 102, 811-815.

[18] Ansell, J. (2007) Factor Xa or thrombin: Is factor Xa a better target? Journal of Thrombosis and Haemostasis, 5, 60-64.

[19] Mann, K.G., Brummel, K. and Butenas, S. (2003) What is all that thrombin for? Journal of Thrombosis and Haemostasis, 1, 1504-1514. doi:10.1046/j.1538-7836.2003.00298.x

[20] Kubitza, D. and Haas, S. (2006) Novel factor Xa inhibitors for prevention and treatment of thromboembolic diseases. Expert Opinion Investigational Drugs, 15, 843-855. doi:10.1517/13543784.15.8.843

[21] Stangier, J., Rathgen, K., Stahle, H., Gansser, D. and Roth, W. (2007) The pharmacokinetics, pharmacodynamics and tolerability of dabigatran etexilate, a new oral direct thrombin inhibitor, in healthy male subjects. British Journal of Clinical Pharmacology, 64, 292-303.
[22] Stangier, J., Rathgen, K., Stahle, H., et al. (2009) Coadministration of dabigatran etexilate and atorvastatin: Assessment of potential impact on pharmacokinetics and pharmacodynamics. American Journal of Cardiovascular Drugs, 9, 59-68.

[23] Connolly, S.J., Ezekowitz, M.D., Yusuf, S., et al. (2009) Dabigatran versus warfarin in patients with atrial fibrillation. The New England Journal of Medicine, 361, 11391151.

[24] Wann, L.S., Curtis, A.B., Ellenbogen, K.A., et al. (2011) 2011 ACCF/AHA/HRS focused update on the management of patients with atrial fibrillation (update on Dabigatran): A report of the American college of cardiology foundation/American heart association task force on practice guidelines. Circulation, 123, 1144-1150.

[25] Patel, M.R., Mahaffey, K.W., Garg, J., et al. (2011) Rivaroxaban versus warfarin in nonvalvular atrial fibrillation. The New England journal of medicine, 365, 883-891.

[26] Rocket, AF Study Investigators. (2010) Rivaroxaban-once daily, oral, direct factor Xa inhibition compared with vitamin $\mathrm{K}$ antagonism for prevention of stroke and embolism trial in atrial fibrillation: Rationale and design of the Rocket AF Study. American Heart Journal, 159, 340-347.

[27] Granger, C.B., Alexander, J.H., McMurray, J.J., et al. (2011) Apixaban versus warfarin in patients with atrial fibrillation. The New England Journal of Medicine, 365, 981-992.

[28] Eikelboom, J.W., O’Donnell, M., Yusuf, S., et al. (2010) Rationale and design of AVERROES: Apixaban versus acetylsalicylic acid to prevent stroke in atrial fibrillation patients who have failed or are unsuitable for vitamin $\mathrm{K}$ antagonist treatment. American Heart Journal, 159, 348-353.

[29] Connolly, S.J., Eikelboom, J., Joyner, C., et al. (2011) Apixaban in patients with atrial fibrillation. The New England Journal of Medicine, 364, 806-817. doi:10.1056/NEJMoa1007432

[30] Lassen, M.R., Raskob, G.E., Gallus, A., et al. (2009) Apixaban or enoxaparin for thromboprophylaxis after knee replacement. The New England Journal of Medicine, 361, 594-604.

[31] Lassen, M.R., Raskob, G.E., Gallus, A., et al. (2010) Apixaban versus enoxaparin for thromboprophylaxis after knee replacement (ADVANCE-2): A randomised double-blind trial. Lancet, 375, 807-815.

[32] Furugohri, T., Isobe, K., Honda, Y., et al. (2008) DU-176b, a potent and orally active factor Xa inhibitor: In vitro and in vivo pharmacological profiles. Journal of Thrombosis and Haemostasis, 6, 1542-1549.

[33] Ogata, K., Mendell-Harary, J., Tachibana, M., et al. (2010) Clinical safety, tolerability, pharmacokinetics, and pharmacodynamics of the novel factor Xa inhibitor edoxaban in healthy volunteers. The Journal of Clinical Pharmacology, 50, 743-753.

[34] Ruff, C.T., Giugliano, R.P., Antman, E.M., et al. (2010) Evaluation of the novel factor Xa inhibitor edoxaban compared with warfarin in patients with atrial fibrillation: Design and rationale for the Effective aNticoaGulation with factor Xa next generation in atrial fibrillation-thrombolysis in myocardial infarction study 48 (ENGAGE AF- 
TIMI 48). American Heart Journal, 160, 635-641.

[35] Agnelli, G., Haas, S., Ginsberg, J.S., et al. (2007) A phase II study of the oral factor Xa inhibitor LY517717 for the prevention of venous thromboembolism after hip or knee replacement. Journal of Thrombosis and Haemostasis, 5, 746-753.

[36] Eriksson, B.I., Quinlan, D.J., Weitz, J.I. (2009) Comparative pharmacodynamics and pharmacokinetics of oral direct thrombin and factor Xa inhibitors in development. Clinical Pharmacokinetics, 48, 1-22.

[37] Turpie, A.G., Bauer, K.A., Davidson, B.L., et al. (2009) A randomized evaluation of betrixaban, an oral factor Xa inhibitor, for prevention of thromboembolic events after total knee replacement (EXPERT). Thrombosis and haemostasis, 101, 68-76.

[38] Kawamura, M., Konishi, N., Hiroe, K., et al. (2010) Antithrombotic and anticoagulant profiles of TAK-442, a novel factor Xa inhibitor, in a rabbit model of venous thrombosis. Journal of Cardiovascular Pharmacology, 56, 156-161. doi:10.1097/FJC.0b013e3181e2bfcf

[39] Eriksson, B.I., Turpie, A.G., Lassen, M.R., et al. (2007) A dose escalation study of YM150, an oral direct factor $\mathrm{Xa}$ inhibitor, in the prevention of venous thromboem- bolism in elective primary hip replacement surgery. Journal of Thrombosis and Haemostasis, 5, 1660-1665.

[40] Weitz, J.I., Cao, C., Eriksson, B.I., et al. (2010) A dosefinding study with TAK-442, an oral factor Xa inhibitor, in patients undergoing elective total knee replacement surgery. Thrombosis and haemostasis, 104, 1150-1157.

[41] Bauer, K.A. (2001) Fondaparinux sodium: A selective inhibitor of factor Xa. American Journal of HealthSystem Pharmacy, 58, S14-17.

[42] Turpie, A.G., Bauer, K.A., Eriksson, B.I. and Lassen, M.R. (2002) Fondaparinux vs enoxaparin for the prevention of venous thromboembolism in major orthopedic surgery: A meta-analysis of 4 randomized double-blind studies. Archives of Internal Medicine, 162, 1833-1840.

[43] Strzelczyk, A., Haag, A., Raupach, H., et al. (2010) Prospective evaluation of a post-stroke epilepsy risk scale. Journal of Neurology, 257, 1322-1326. doi:10.1007/s00415-010-5520-9

[44] Pendlebury, S.T. and Rothwell, P.M. (2009) Prevalence, incidence, and factors associated with pre-stroke and post-stroke dementia: A systematic review and metaanalysis. Lancet Neurology, 8, 1006-1018. doi:10.1016/S1474-4422(09)70236-4 